\title{
Extruded Pet Food Development from Meat Byproducts using Extrusion Processing and its Quality Evaluation
}

\author{
Javeed Akhtar* and Mohd Ali Khan
}

Department of Post-Harvest Engineering and Technology, Faculty of Agriculture Science, AMU, Aligarh, India

\begin{abstract}
The studies were carried out to development and quality evaluation of extruded pet food by utilization of buffalo meat byproducts like livers, trims and agro wastes namely sorghum, oat and corn flour. The quality of the extruded pet food was evaluated on the basis of qualities characteristics namely $\mathrm{pH}$, fat content, protein content, ash content, and TBA number. Protein content and fat content of fresh pet food were found in the following ranges $15.84 \%$ and $10.64 \%$ respectively. The $\mathrm{pH}$ of extruded pet food was significantly decreased. The ash content, TBA number and $\mathrm{pH}$ content were $2.43 \%, 0.605 \mathrm{mg} / \mathrm{kg}$ and $6.29 \%$ in fresh condition. During ambient storage $\mathrm{pH}$ values was found to decrease consistently. Protein content was found to decrease significantly. The Sorghum, oat and corn flour incorporation, significantly affected on quality of extruded pet food samples.
\end{abstract}

Keywords: Extrusion technology; Pet food; Chemical treatment; Quality attributes and storage

\section{Introduction}

Extrusion cooking technology is used for the manufacture of commercial dry food for canine and feline diets: about $95 \%$ of dry pet foods are extruded [1]. In this processing technology a mixture of ingredients is steam conditioned, compressed and forced through the die of the extruder [2]. The reason for the widespread use of extrusion cooking to produce pet diets is the versatility of this technology to mix diets and functionally improve, detoxify, sterilize and texturize a large variety of food commodities and food ingredients. A combination of moisture, pressure, residence time, temperature and mechanical shear is used for these reactions and transformations [3]. Pet food by extrusion processing focuses on the production of feeds for animals with a high nutritional value but low economic usefulness. Nonetheless, balancing the components and gentle processing are at the center of the related quality considerations. Extrusion is therefore increasingly proving to be the right tool for modern pet food.

Extrusion has become a very important process in the manufacture of pet food. Extrusion machines use single or twin screws to transport, mix, knead, shear, shape, and/or cook multiple ingredients into a uniform food product by forcing the ingredient mix through shaped dies to produce specific shapes and lengths. Extrusion provides the foundation for continuous production. Food extruders are used to produce pasta and other cold formed products, cereals, snacks, pet food, feed, confectionery products (including chewing gum, licorice, and marsh mallows), modified starches for soup, baby food, and instant foods, beverage bases, and textures vegetable proteins. Single-screw extruders have been in use for continuous cooking and in the forming of ready-to-eat (RTE) cereals as a one-step process since the 1960s. Twin-screw extruders were in common use in food production by the 1980s. A gradual shift towards prepared dog food was observed over the review period and now dog owners have been more willing to spend on food for their pet than ever before. This trend has spawned an entire industry, with a growing emphasis on dog food.

Now dog food is a multibillion dollar industry. The growth difference in India is $30-40 \%$. India has an estimated population of 1.5 million pedigreed dogs [4]. The export market is a big revenue earner with around Rs. 15 crore turnovers compared to Rs.2.5-3 crore from the domestic market (Newspaper report, Times of India, 18 June 2005). According to American President George Bush's (May 5 ,
2008, HT), Indians spent 20 million dollars in feeding their pets in 2004, a figure that up to million dollars in 2007. This gradual increase in commercial pet food market was because of two factors this is the role of veterinarians in educating consumers and selling pet food with vets currently accounting for as much as $44 \%$ sales of commercially prepared foods (HT, May 5, 2008). Second, thing is that most of the mid-priced and premium pet food brands in India are imported.

The government reduction of the import duties on pet food in 2007 provides a boost to both manufacturer and importers. This reduction in import duties also signals the first indication of government's softening towards the pet food and pet care products industry. The food industry offers strong growth opportunities in the forecast period. Our country is diversified and developing country here those ingredients which makes the pet food more nutrition, safe, healthy and cheap are easily available as a by products and waste of food industries and slaughterhouse wastes. In developing countries of Asia where meat from ruminants constitute only about $21.0 \%$ of the total meat production, buffalo meat is about $11.52 \%$ of the total ruminant meat, and about $2.7 \%$ of all meat produced in the region. The average annual growth rate in production was about $1.3 \%$. Undoubtedly, majority of world's buffalo meat is Asian, representing $91.89 \%$ and with volume of $3.08 \mathrm{M}$ tons in 2008 (FAO, 2010). World Bank survey India is the largest producer of food grains and milk and second largest in fruits and vegetables in the world. Yet nearly $40 \%$ of its food is wasted it means country losses more than Rs.58,000 crore worth of agricultural food items, due to lack of post harvesting infrastructure such as cold chains, transportation and storage facilities [5].

The present study was undertaken for the development and quality evaluation of agro-processing byproducts incorporated extruded dog

*Corresponding author: Javeed Akhtar, Department of Post-Harvest Engineering and Technology, Faculty of agriculture Science, AMU, Aligarh, India, Tel: +91-572703305; E-mail: er.jakhtar@gmail.com

Received November 16, 2015; Accepted December 08, 2015; Published December 17, 2015

Citation: Akhtar J, Khan MA (2015) Extruded Pet Food Development from Meat Byproducts using Extrusion Processing and its Quality Evaluation. J Food Process Technol 7: 539. doi:10.4172/2157-7110.1000539

Copyright: (c) 2015 Akhtar J, et al. This is an open-access article distributed unde the terms of the Creative Commons Attribution License, which permits unrestricted use, distribution, and reproduction in any medium, provided the original author and source are credited. 
food. Agro-processing byproducts used were meat byproducts along with grains, fruit and vegetable. Quality evaluation has been done in terms of physicochemical analysis. The quality of fresh extruded dog food was evaluated on the basis of physico-chemical characteristics namely $\mathrm{pH}$, fat content, protein content and TBA number. The samples of dog food were packed using heat sealing machine in combination film and kept at ambient temperature for 120 days. It was found that the shape of extrudates was stick form.

\section{Materials and Methods}

\section{Materials collection}

Sample collection of agro processing byproducts: Freshly slaughtered edible or inedible byproducts namely, liver, kidney, blood and bones of Indian buffalos of 5 years of age were collected. The samples were immediately transferred to the laboratory in ice for further processing. The samples were stored in a deep freezer at $-20^{\circ} \mathrm{C}$ until used.

Sample collection of agro wastes: All the collected agro processing byproducts including sorghum, wheat, corn and oat were also collected from the market of Aligarh. All the collected material firstly cleaned, sieved washed and dried in tray drier oven at $60^{\circ} \mathrm{C}$ temperature.

\section{Manufacturing process of extruded pet food}

The buffalo meat byproducts were fed into mincer for making liquid material and all cereals ingredients sorghum, oat, corn flour were grinded in grinder to obtained fine powder. The liquid meat byproducts materials and cereals fine powder were mixed in the mixer to obtain good mixed materials after complete mixing of both materials added other ingredient are added and mixed then fed into twin screw extruder for preparation of rod type extruded pet food. Extruder was operated at $170^{\circ} \mathrm{C}$ and at $300 \mathrm{rpm}$ screw speed product was complete cooked drawn the process of extrusion and types extruded pet food were collected and packed by heat sealing method in combination film/pouch and stored at ambient temperature for studying their quality characteristics as a function of time.

\section{pH measurement}

$10 \mathrm{~g}$ of developed dog food samples were taken along with $50 \mathrm{ml}-$ distilled water homogenized in a mixer grinder. The ground sample was filtered and the $\mathrm{pH}$ was determined by dipping the combined glass electrode of a digital $\mathrm{pH}$ meter (Khera model, Indian make) into the filtrate.

\section{Determination of ash content}

According to Association of Official Analytical Chemist (AOAC) 1990 method, dried sample was weighted into crucible and ignited at $550^{\circ} \mathrm{C}$ for $12-18 \mathrm{hrs}$ in the muffle furnace (make Tango). It was then taken out and allowed to cool for a moment and then placed in desiccators until cooled and finally weighed to constant weight. Following formula was used to calculate ash content (Figure 1).

$$
\text { Ash content }(\%)=\frac{\text { final weight of ash }}{\text { initial weight of sample }} \times 100
$$

\section{Determination of fat content}

The Soxhlet method has been suggested by Association of Official Analytical Chemist (AOAC) of year 1971 was used for dog food product fat extraction.

The following formula used to express fat content of the sample.

$$
\text { Fat } \%=\frac{\text { Gram of fat in sample }}{\text { Gram of sample }} \times 100
$$

\section{Determination of protein content}

The protein content of dog food sample was evaluated according to Association of Official Analytical Chemist (AOAC, 1990) method. In this method Kjeldhal apparatus was used. The dog food sample was digested with sulphuric acid in the presence of catalyst. The total organic nitrogen was converted to ammonium sulphate. The digestion was neutralized with alkali and distilled into a boric acid solution. The borate anions formed were titrated with standardized acid, which was then converted to nitrogen in the sample. The result of the analysis represented crude protein of the food since nitrogen also comes from non-protein component.

$\%$ Protein $=\% \mathrm{~N} \times 6.25$

A reagent blank should be run to subtract nitrogen from the sample nitrogen.

$$
\begin{aligned}
& \% N=\frac{N H C l \times \text { Corrected acid value }}{g \text { of sample }} \times \frac{N}{\text { mole }} \times 100 \\
& \% \mathrm{~N} \times 6.25=\% \text { Protein }
\end{aligned}
$$

\section{Measurement of thiobarbutyric acid (TBA) number}

For Thiobarbituric acid number (TBA), evaluation TBA reagent was prepared according to Pearson by dissolving $0.2883 \mathrm{~g}$ of Thiobarbityric acid in sufficient quantity of $90 \%$ and slight warming, the volume being made up to $100 \mathrm{ml}$ with $90 \%$ acetic acid. TBA number was measured by the method described by Strange et al. For this $5 \mathrm{ml}$ of TCA extract was mixed with $5 \mathrm{ml}$ of TBA reagent in a test tube. The test tube was kept in a water bath at $100^{\circ} \mathrm{C}$ for 30 minutes along with another test tube containing a blank of $5 \mathrm{ml}$ of $10 \%$ TCA and $5 \mathrm{ml}$ TBA reagent. After cooling the tube in running water for about $10 \mathrm{~min}$, the absorbance was measured at $530 \mathrm{~nm}$ in spectrophotometer and reported as TBA number

\section{Statistical Analysis}

\section{Standard deviation}

The best and most commonly used statistical evaluation of the precision of analytical data is the standard deviation. The standard deviation measures the spread of the experimental values and gives a good indication of how close the values are to each other. Samples were prepared in three replication and data obtained for selected quality parameters were analyzed for mean and standard deviations using following formula:

$\mathrm{SD}= \pm \sqrt{ } \sum\left(\mathrm{X}_{\mathrm{i}}-\mathrm{X}\right)^{2} / \mathrm{n}$

Where,

$$
\begin{aligned}
& \mathrm{X}_{\mathrm{i}}=\text { individual sample values } \\
& \mathrm{X}=\text { mean of individual samples } \\
& \mathrm{n}=\text { total population of sample }
\end{aligned}
$$

\section{Results and Discussion}

\section{Effect on $\mathrm{pH}$ of extruded pet food}

The $\mathrm{pH}$ values of the agro processing waste incorporated extruded dog food were in the neutral range (6.28-6.18). The extruded dog food 


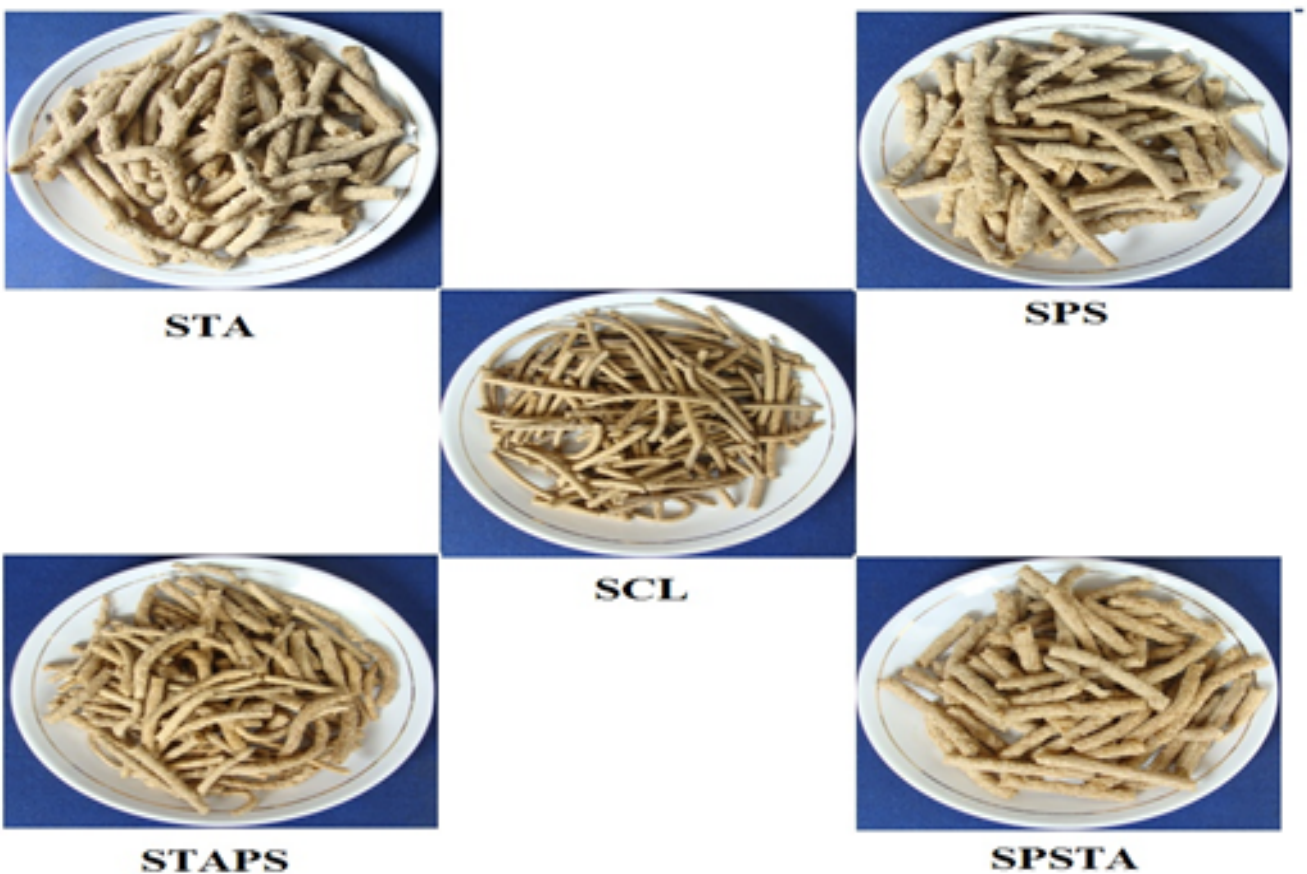

Figure 1: Developed extruded pet foods.

control sample (SCL) which was developed by incorporation of buffalo meat byproducts along with the grains and vegetable shows the $\mathrm{pH}$ value 6.31 after preparation. The effects of treatment were noticed on $\mathrm{pH}$ values of agro processing waste incorporated extruded dog food and it was observed that the $\mathrm{pH}$ of samples STA (with $0.5 \%$ a-tocopherol acetate), SPS ( $0.5 \%$ potassium sorbet), STAPS (combination of $0.5 \%$ $a$-tocopherol $+1 \%$ potassium sorbet) and SPSTA (combination of $0.5 \%$ potassium sorbet $+1 \%$ a-tocopherol acetate) were $6.28,6.27,6.28$ and 6.26 respectively on day 1 of storage (Figure 2).

As a function of time the $\mathrm{pH}$ values were significantly changed during storage with respect of treatment. The $\mathrm{pH}$ of buffalo meat byproducts incorporated extruded dog food control sample (SCL) reached to 6.27 whereas the $\mathrm{pH}$ of STA (with $0.5 \%$ a-tocopherol acetate treated), SPS (0.5\% potassium sorbet treated), STAPS (combination of $0.5 \%$ a-tocopherol $+1 \%$ potassium sorbet treated) and SPSTA (combination of $0.5 \%$ potassium sorbet $+1 \%$ a-tocopherol acetate treated) after 120 days of storage reached to $6.16,6.20,6.23$ and 6.21.The least fall in the $\mathrm{pH}$ value was noticed in STAPS (combination of $0.5 \%$ a-tocopherol $+1 \%$ potassium sorbet) in comparison to the other treated extruded dog food samples. Mild denaturation of proteins during extrusion cooking may be responsible for the declined of $\mathrm{pH}$ during storage of 120 days. During storage the $\mathrm{pH}$ was declined significantly.

\section{Effect on Protein content of extruded pet food}

The protein component in pet foods can constitute between 25 and $70 \%$ of the dry matter (DM) [2]. Dogs required relatively high proportion of protein because of carnivorous nature. Effects of extrusion on the protein component of buffalo meat byproducts incorporated extruded dog foods was evaluated (Figure 3).

The protein content of buffalo meat byproducts incorporated control sample (SCL) was initially found 15.84 which on further storage

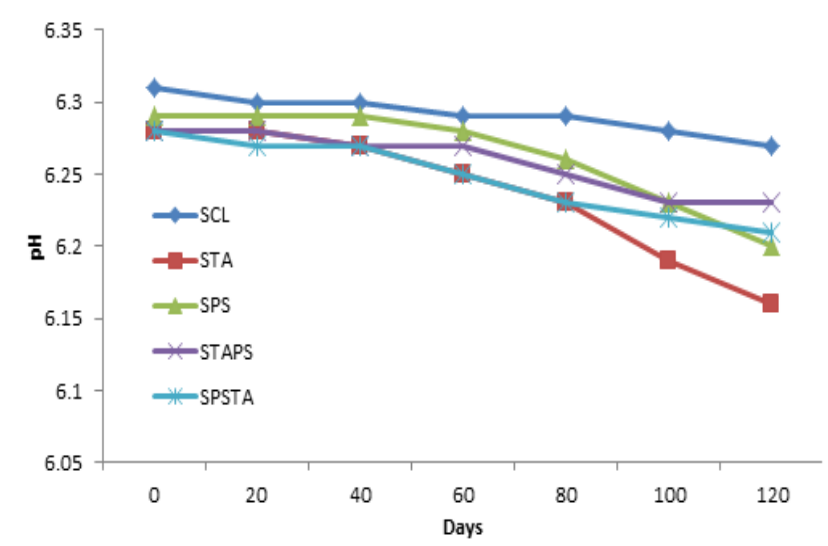

Figure 2: Effect on $\mathrm{pH}$ of extruded pet food during storage of 120 days at ambient temperature.

continuously decreased with increased storage period. Where the $0.5 \%$ a-tocopherol acetate treated sample (STA) shows no significant change in protein content up to 60 days of storage but later the reduction were with the increasing storage time the similar condition were also noticed in $0.5 \%$ potassium sorbet treated extruded dog food. The preservative system STAPS (combination of $0.5 \%$ a-tocopherol $+1 \%$ potassium sorbet treated) and SPSTA (combination of $0.5 \%$ potassium sorbet + $1 \%$ a-tocopherol acetate treated) both shows the marginally declined protein content in the composition of extruded dog food.

An undesirable effect of heat treatment during extrusion causes protein denaturation because of Millard reactions which can make them more susceptible to digestive enzymes and therefore improve the digestibility of protein of extruded dog food. It is observed that 


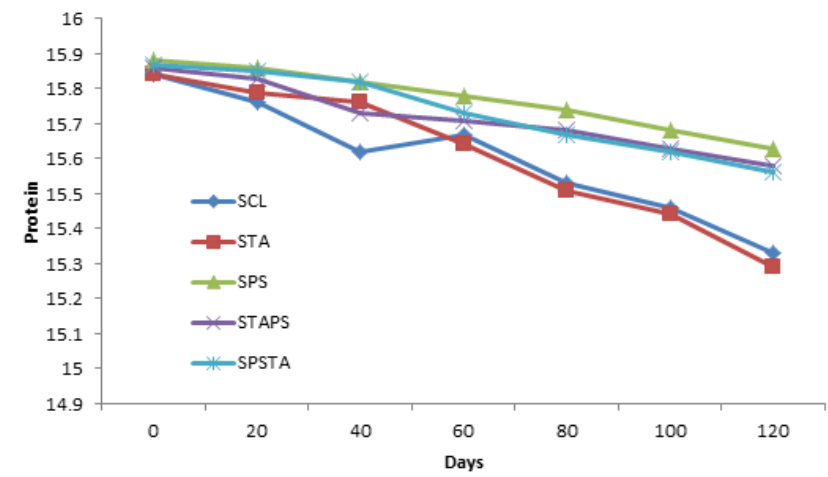

Figure 3: Effect on Protein content of extruded pet food during storage of 120 days at ambient temperature.

in all four treated samples more or less reduction in protein content during storage may be because of weak antioxidant systems namely $a$-Tocopherol in combination or individual level as it was found unable to inhibit the protein oxidation in atmospheric packaging Marianne et al [6] also noticed that protein oxidation during storage beef patties treated with antioxidants namely ascorbic acid and $\alpha$-Tocopherol and packed with atmospheric packaging.

\section{Effects on Fat Content of extruded pet food}

The effect of preservative namely $\alpha$-Tocopherol and potassium sorbet individual or in combination treated buffalo meat byproducts incorporated in combination with grain, vegetable and fruits extruded dog was evaluated and discussed below. It may be noted from the figure that the fat content of treated or non-treated extrudates significantly degraded during storage study of 120 days. The buffalo meat byproducts incorporated control sample (SCL) on day one shows 10.64 fat content which on further storage rapidly reduced with increasing storage period.

The fat content values of $0.5 \%$ a-tocopherol acetate treated (STA), $0.5 \%$ potassium sorbet treated (SPS), combination of $0.5 \%$ a-tocopherol $+1 \%$ potassium sorbet treated (STAPS) and combination of $0.5 \%$ potassium sorbet $+1 \% \alpha$-tocopherol acetate treated (SPSTA) were 10.65 , $10.66,10.68$ and 10.67 respectively fresh samples and finally reached to $10.46,10.49,10.43$ and 10.39 respectively after 120 days of storage. It is observed that the preservative system in combination works quite better than individual because initially the reductions in fat content were negligible. It is also concluded that from the data shown in Figure 3 at initial level the preservative system works well but as increasing storage period these system were unable to provide protection and that samples slowly get degraded in presence of known antioxidant a-tocopherol acetate which is not able to work in atmospheric system of packaging. Marianne et al., 2006 also noticed that protein and fat oxidation was occurred in presence of antioxidants namely ascorbic acid and $\alpha$-Tocopherol treated beef patties in atmosphere packaging system during storage. Oxidation rate is affected by many factors such as fat type, fat content, moisture content and expansion degree where the unsaturation in fats increases the preservation challenge $[7,8]$ (Figure 4).

\section{Effect on ash content of extruded pet food}

Ash has been shown to be an effective content for dog foods. Due to the high dietary levels of animal by-products, the levels of ash content in our dog foods were high which shows the higher mineral content. The ash content of five types of dog foods is shown in figure the ash content of SCL control sample without ( $\alpha$-tocopherol acetate and potassium sorbet) treatment was $2.44 \%$ on day one. Where the ash content of STA (with $0.5 \%$ a-tocopherol acetate treated), SPS ( $0.5 \%$ potassium sorbet treated), STAPS (combination of $0.5 \%$ a-tocopherol, $1 \%$ potassium sorbet treated) and SPSTA (combination of $0.5 \%$ potassium sorbet, $1 \%$ a-tocopherol acetate treated) were $2.43 \%, 2.42 \%, 2.42 \%$, and $2.42 \%$ respectively on day 1 of storage. As a function of time the reduction in ash content were noticed during storage study of 120 days. The samples treated with combination of $0.5 \%$ a-tocopherol, $1 \%$ potassium sorbet treated (S4TAPS) significantly shows the minimum degradation of mineral content with reflecting marginal decrease in ash content values in throughout storage. There were significant differences $(p<0.05)$ in ash content $[9,10]$. The ash contents were higher. Ash constitutes the organic matter which is also difficult for animal digestion but required in trace amounts. As ash does not contain any energy, so it would naturally lower the overall energy of the feed (Figure 5).

\section{Effect on TBA values of extruded pet food}

Thiobarbituric acid number (TBA), of treated and untreated extrudates to measures the oxidative rancidity, was analyzed and shown in figure. TBA reactive materials were measured as milligrams of malondialdehyde per kg of sample (Pearson 1971). Malondialdehyde is released from the endoperoxides that are formed from lipid peroxidation of polyunsaturated fatty acids. The fresh extruded dog food (control sample, SCL) had a TBA value of $0.605 \mathrm{mg} / \mathrm{kg}$ significantly increased with increasing storage period and finally reached to $0.822 \mathrm{mg}$ (Figure $6)$.

The fresh extruded dog food of STA (with $0.5 \%$ a-tocopherol acetate treated), SPS ( $0.5 \%$ potassium sorbet treated), STAPS (combination of $0.5 \%$ a-tocopherol, $1 \%$ potassium sorbet treated) and SPSTA (combination of $0.5 \%$ potassium sorbet, $1 \%$ a-tocopherol acetate treated) were $0.602 \mathrm{mg} / \mathrm{kg}, 0.604 \mathrm{mg} / \mathrm{kg}, 0.601 \mathrm{mg} / \mathrm{kg}$ and $0.603 \mathrm{mg} /$ $\mathrm{kg}$ respectively but were not significantly different among preservative system in throughout the 120 days storage study $[11,12]$. As a function of time the TBA values is increased with increasing storage study of 120 days. The samples treated with combination of $0.5 \%$ a-tocopherol, $1 \%$ potassium sorbet treated (STAPS) significantly shows the marginally inclined TBA values in throughout storage.

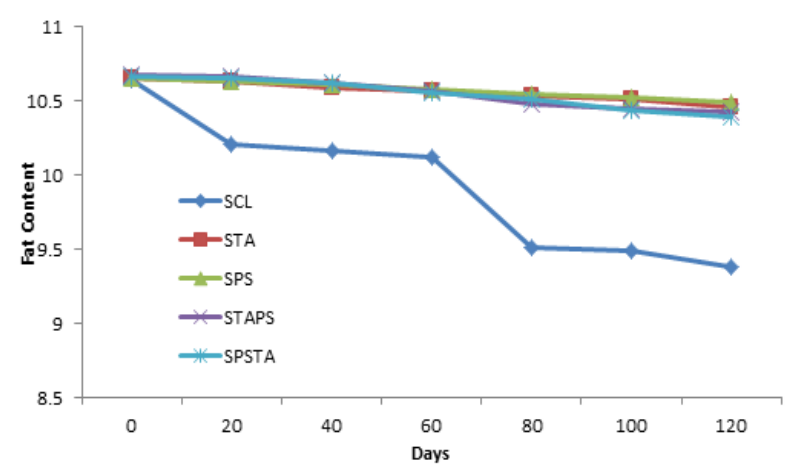

Figure 4: Effect on fat content of extruded pet food during storage of 120 days at ambient temperature. 


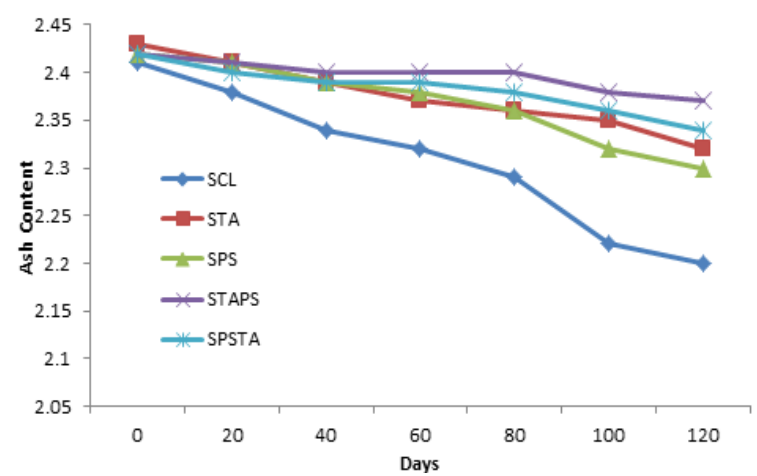

Figure 5: Effect on ash content of extruded pet food during storage of 120 days at ambient temperature.

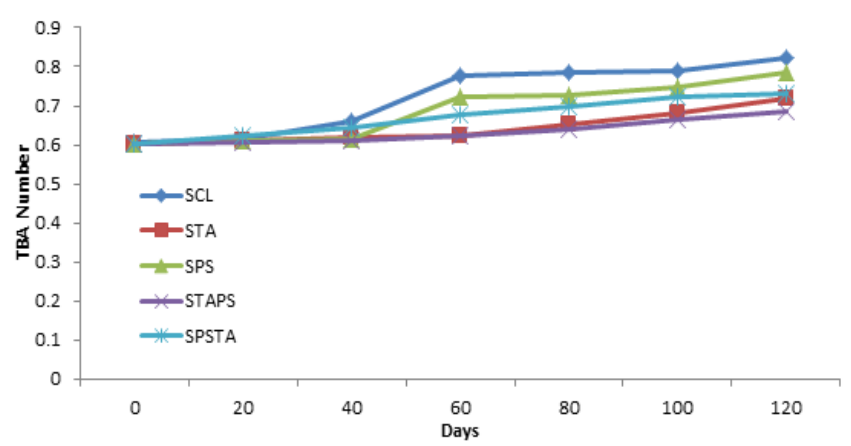

Figure 6: Effect TBA numbers of extruded pet food during storage of 120 days at ambient temperature.

\section{Conclusions}

Cooking at high temperature, dehydration and packaging etc. of buffalo meat byproducts extruded dog food in combination with preservatives namely potassium sorbet and $\alpha$-Tocopherol were proved to be effective method for controlling microflora and make them shelf stable. The deterioration of protein and fat content among these characteristics reflect that antioxidant system was not able to work in atmosphere packaging this also shows that $\alpha$-Tocopherol, slowly lose its working efficacy in air packaging individual or in combination. Where potassium sorbet was successfully inhibit the mold growth but not work as a powerful barrier for against rancidity.

The decreasing in $\mathrm{pH}$ was not related to spoilage of the product. The fall in $\mathrm{pH}$ values in both treated as well as untreated (control) samples is due to denaturation or oxidation of lipid and protein during extrusion cooking at high temperature and atmospheric pressure. All these factors may be responsible to alter the acidity as a result $\mathrm{pH}$ decreased with increasing storage period.

The increasing trend in TBA values indicated that natural antioxidant $\alpha$-Tocopherol individual or in combination of potassium sorbet was less stable in atmosphere packaging. Finally, after 120 days of storage there was no quality deterioration found in any sample but the rancidity value of meat byproducts incorporated extrudates were increasing with increasing storage period which later will not be suitable for the dog health.

\section{Acknowledgments}

The authors thank Staffs from Department of Post-Harvest Engineering and Technology, Faculty of agriculture Science, A.M.U, Aligarh, India for its help in the conduction of experimental procedures. Also, the authors are grateful for the financial support of Aligarh Muslim University, Aligarh India.

\section{References}

1. Spears JK, Fahey GC (2004) Resistant starch as related to companion animal nutrition. JAOAC Int 87: 787-791.

2. Rokey G, Plattner B (1995) Process description: pet food production. Wenger Mfg Inc, Sabetha, KS USA.

3. Cheftel JC (1986) Nutritional effects of extrusion cooking. Food Chem 20 : 263-283.

4. Atrey Arun (2001) Petcare Industry: Challenges and the road ahead.

5. Mishra PK (2008) 72 percent of India's fruit, vegetable produce goes waste, New Delhi.

6. Marianne NL, Marchen SH, Leif $\mathrm{H}$ (2006) The combined effect of antioxidants and modified atmosphere packaging on protein and lipid oxidation in beef patties during chill storage. International Journal of Meat science 76: 226-233.

7. Lin S, Hsieh F, Huff HE (1997) Effects of lipids and processing conditions on lipid oxidation of extruded dry pet food during storage. Anim Feed Sci Technol 71: 283-194.

8. Deffenbaugh (2007) Optimizing pet food, aquatic and livestock feed quality Agrimedia $\mathrm{GmbH}$, Clenze, Germany: 327-342.

9. AFFCO (2007) Compendium of Association of American Feed Control Officials

10. Parsons CM (1997) Protein and amino acid quality of meat and bone meal poult sc76: $361-368$.

11. Ranganna S (2000) In Hand Book of Analysis and Quality Control for Fruit and Vegitable Products. Tata Mc Grawhill Pubco, New Delhi.

12. Shrivastva RP, Sanjeev K (2003) The Book of Fruit and vegetable preservation principles and practices by (I.B.D. CO) Lucknow. 